\title{
Growth and optical properties of peculiar ZnO tetrapods
}

\author{
Fa-Quan He and Ya-Pu Zhao ${ }^{1}$ \\ State Key Laboratory of Non-linear Mechanics (LNM), Institute of Mechanics, Chinese Academy of \\ Sciences, Beijing 100080, People's Republic of China \\ E-mail: yzhao@lnm.imech.ac.cn
}

Received 5 January 2006, in final form 24 March 2006

Published 5 May 2006

Online at stacks.iop.org/JPhysD/39/2105

\begin{abstract}
Regular $\mathrm{ZnO}$ tetrapods with different morphologies have been obtained on $\mathrm{Si}(100)$ substrate via the chemical vapour deposition approach. Varying the growth temperature and gas rate, we have obtained different structured $\mathrm{ZnO}$ materials: tetrapods with a large hexagonal crown, a flat top and a small hexagonal crown. The results suggest that these tetrapods are all single crystals with a wurtzite structure that grow along the (0001) direction. However, photoluminescence spectra shows that their optical properties are quite different: for those with large hexagonal crown, the green emission overwhelms that of the near band-edge (NBE) ultraviolet (UV) peak, while others have only a strong NBE UV peak at $\sim 386 \mathrm{~nm}$.
\end{abstract}

\section{Introduction}

Micro- or nanosize inorganic materials, especially semiconductor materials, have attracted much attention in recent years. As a promising semiconductor with potential applications in light emitting diodes [1,2], transistors [3], sensors [4,5], solar cells [6], optical switches [7], photo-catalysis [8], surface acoustic waveguides [9] and piezoelectric transducers [10], $\mathrm{micro} /$ nanosize $\mathrm{ZnO}$ has invoked worldwide intensive investigations. Naturally, shape and dimensionality play important roles in the properties and applications of nanomaterials. So far, $\mathrm{ZnO}$ nanomaterials with exciting morphologies, such as nanobelts [11], nanowires [12] and nanohelices [13], have been reported. Nowadays, numerous studies have been focused on the preparation and properties of $\mathrm{ZnO}$ tetrapods because they possess remarkable optical, electric, magnetic and mechanical properties; thus they have prospective applications in transistors [3], sensors [4,5], etc.

In this paper, we present a simple method to grow some regular tetrapods at temperatures around $600-700^{\circ} \mathrm{C}$. The as-synthesized products exhibit unique optical properties which shed light on potential applications in the fields of nanoelectronics and nanooptics.

\section{Experimental details}

These regular $\mathrm{ZnO}$ tetrapods were synthesized via a simple catalyst-free vapour evaporation deposition process. P-type

\footnotetext{
1 Author to whom any correspondence should be addressed.
}

silicon (100) wafer was first cleaned with a standard treatment in Piranha solution $\left(20 \% \mathrm{H}_{2} \mathrm{SO}_{4}+10 \% \mathrm{H}_{2} \mathrm{O}_{2}\right)$ for about $30 \mathrm{~min}$ at a temperature of $90^{\circ} \mathrm{C}$, then ultrasonically cleaned with deionized water and finally dried naturally. An alumina boat $(8.0 \mathrm{~mm} \times 1.2 \mathrm{~mm} \times 1.0 \mathrm{~mm})$ containing $2.0 \mathrm{~g} \mathrm{Zn}$ powder (99.999\%) was inserted into the centre of the horizontal quartz tube that was placed horizontally in a high-temperature tubular furnace $(50 \mathrm{~mm}$ in inner diameter and $1200 \mathrm{~mm}$ in length). A silicon substrate $(15 \mathrm{~mm} \times 5 \mathrm{~mm} \times 0.38 \mathrm{~mm})$ was laid face-down on the boat with the long edges parallel to the quartz tube. The nearest distance between the edge and the $\mathrm{Zn}$ sources was about $6.0 \mathrm{~mm}$. The system was first evacuated for about $10 \mathrm{~min}$, and then $\mathrm{Ar}$ was switched on to fill the quartz tube in order to drive off the residual $\mathrm{O}_{2}$ in it. Subsequently, the sources were heated to the desired temperature $\left(630^{\circ} \mathrm{C}\right.$ and $680^{\circ} \mathrm{C}$, respectively) at a rate of $30^{\circ} \mathrm{C} \mathrm{min}^{-1}$. Immediately, a flow of $\mathrm{Ar}$ at a rate of about $300 \mathrm{sccm}$ and $\mathrm{O}_{2}$ at about $10-30 \mathrm{sccm}$ was introduced into the system and maintained for $10-30 \mathrm{~min}$. Finally, the flows of $\mathrm{Ar}$ and $\mathrm{O}_{2}$ were shut down, and the furnace was turned off and cooled naturally down to room temperature. Products were collected on the surface of the substrates. The as-prepared $\mathrm{ZnO}$ tetrapods were characterized using $\mathrm{x}$-ray diffraction (XRD, D/MAX-2500), field emission scanning electron microscopy (FESEM FEI SIRION) equipped with energy-dispersive x-ray spectroscopy (EDS), high-resolution field emission transmission electron microscopy (HR-FETEM, JEM 2010F) equipped with selected area electron diffraction (SAED), Raman spectrum (JY-T64000, excitation wavelength: 
$524 \mathrm{~nm}$ ) and the photoluminescence (PL) property (Xe lamp: $325 \mathrm{~nm}$ as the excitation source).

\section{Results and discussion}

To investigate the composition and structure of the obtained samples, the EDS and XRD measurements were employed. The EDS analysis confirms that the synthesized samples are composed of $\mathrm{Zn}$ and $\mathrm{O}$ with no other elements detected. The XRD results show that the samples synthesized at $T=630^{\circ} \mathrm{C}$ and $680^{\circ} \mathrm{C}$ are the same as shown in figure 1 . As can be seen, all peaks are sharp and strong, suggesting that the products are highly crystallized. These peaks agree well with the peaks of the wurtzite-type $\mathrm{ZnO}$ with unit cell constants of $a=3.253 \AA$ and $c=5.209 \AA$.

Figure 2(a) shows typical SEM images of the $\mathrm{ZnO}$ tetrapods synthesized at $T=630{ }^{\circ} \mathrm{C}$ with a flow of $\mathrm{O}_{2}$ at a rate of $15 \mathrm{sccm}$. The as-synthesized products are uniform

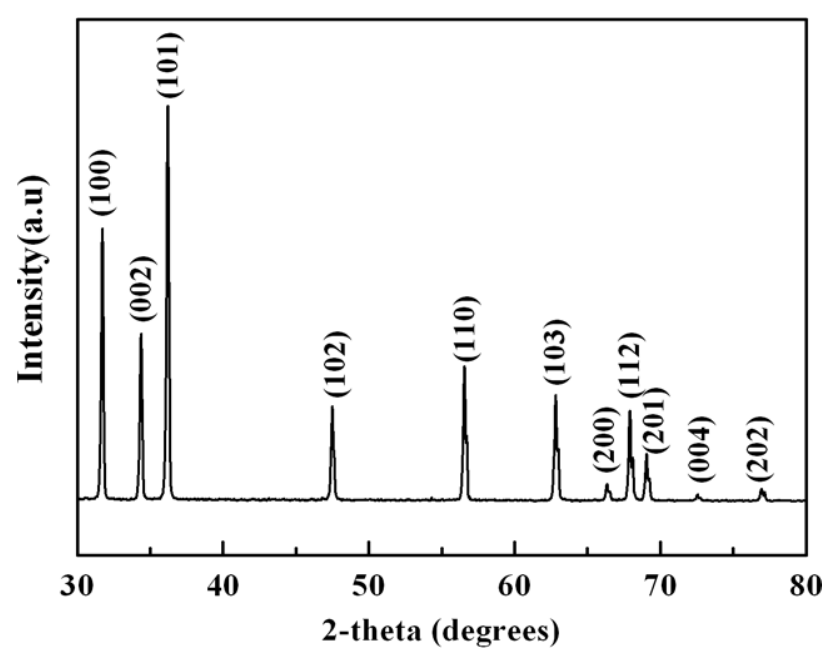

Figure 1. XRD pattern of as-prepared $\mathrm{ZnO}$ tetrapods grown on $\mathrm{Si}(100)$ showing wurtzite structure and high crystallinity.
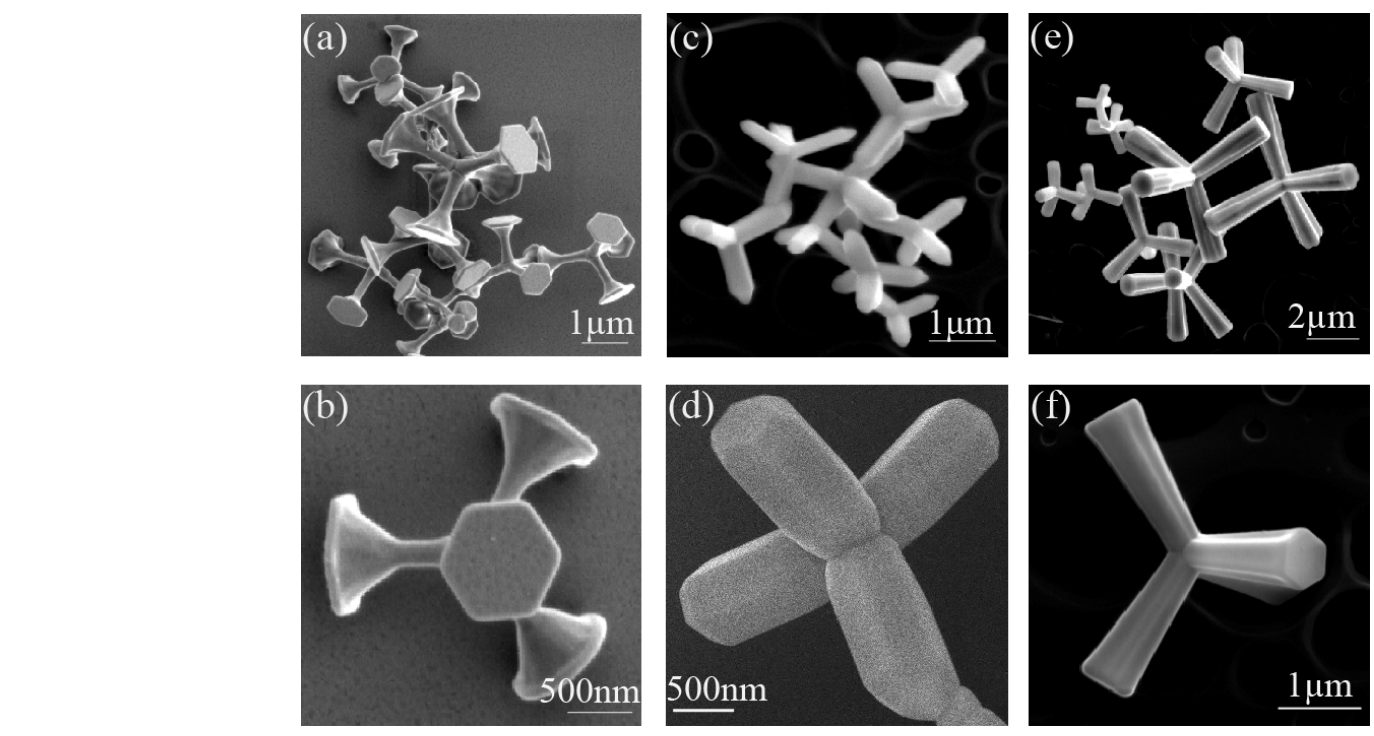

tetrapod-like $\mathrm{ZnO}$ with a large hexagonal crown on each leg. The legs of each unit, as magnified in figure $2(b)$ have a diameter of $100-150 \mathrm{~nm}$, a length of about $1-1.5 \mu \mathrm{m}$; the side length of the hexagonal crown is about $500 \mathrm{~nm}$ and the thickness around $100 \mathrm{~nm}$. The temperature and flow play an important role in the morphology of the products. When the growth temperature was raised to $680^{\circ} \mathrm{C}$ and the flow of $\mathrm{O}_{2}$ was changed to $25 \mathrm{sccm}$, two other different structures of $\mathrm{ZnO}$ resulted, as shown in figures $2(c)-(f)$. These two kinds of $\mathrm{ZnO}$ tetrapods were obtained from different regions of the same substrate: the $\mathrm{ZnO}$ tetrapods with smaller hexagonal crowns shown in figures $2(c)$ and $(d)$ were collected on the upper side of the Si substrate and the other (shown in figures 2(e) and $(f)$ ) on the middle side. The four legs of the former tetapods are a remarkably uniform prism with six sides and faces, and each leg is between $1-2 \mu \mathrm{m}$ in length and about $500 \mathrm{~nm}$ in diameter. But the size of each unit may be different from one another. The top shape of the tetrapods is a regular hexagonal crown (smaller than the legs). Figures $2(e)$ and $(f)$ present a general morphology of the later tetrapods at different magnifications, showing that a unit has four regular legs around $1-2 \mu \mathrm{m}$ in length and $\sim 500 \mathrm{~nm}$ in diameter. Different from the two tetrapods mentioned above, this kind of tetrapod has no crown, and the size of each leg of a unit is smoothly reduced from the top to the centre. A common characteristic for the three kinds of tetrapods is that they have a regular hexagonal top and the cross sections of the legs have an internal angle of $120^{\circ}$.

Further analyses of these $\mathrm{ZnO}$ tetrapods were performed using HRFETEM. Typical TEM images of the $\mathrm{ZnO}$ tetrapods with large hexagonal crown obtained at a temperature of $630^{\circ} \mathrm{C}$ given in figures $3(a)$ and $(b)$ clearly show that the diameter of a leg is $\sim 120 \mathrm{~nm}$. The HRTEM image as shown in figure 3(c) shows that the spacing between adjacent lattice planes is approximately $0.51 \mathrm{~nm}$ corresponding to the (0001) plane of wurtzite-type $\mathrm{ZnO}$. This indicates that the crystals are preferentially oriented in the $c$-axis direction. The SAED patterns confirm that the synthesized products are single

Figure 2. Low and high magnification SEM images of $\mathrm{ZnO}$ tetrapods deposited at different temperatures showing the difference of morphology between these regular tetrapods: $(a),(b) T=630^{\circ} \mathrm{C}, \mathrm{O}_{2}: 15 \mathrm{sccm}, \mathrm{Ar}: 300 \mathrm{sccm}$ and $(c)-(f) T=680{ }^{\circ} \mathrm{C}, \mathrm{O}_{2}: 25 \mathrm{sccm}, \mathrm{Ar}$ : $300 \mathrm{sccm}$. 

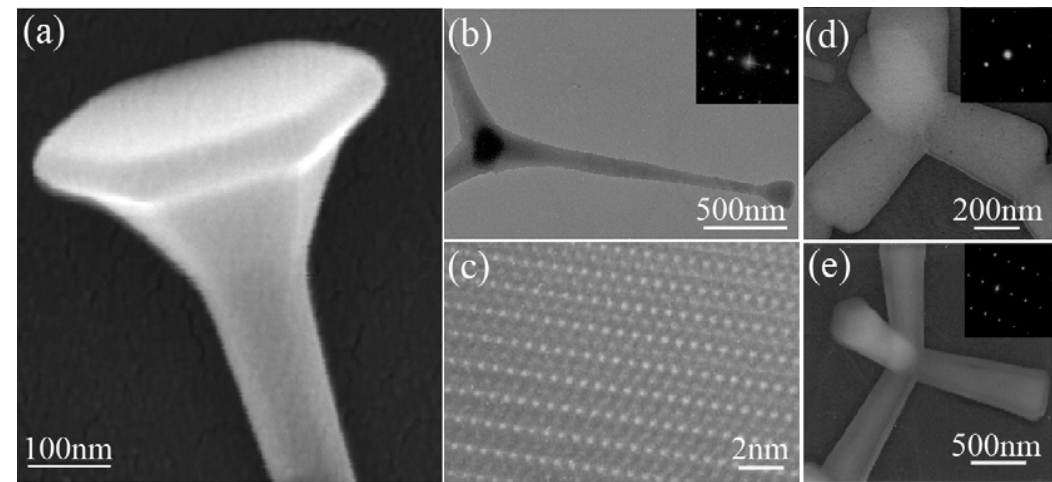

Figure 3. $(a),(b),(d),(e)$ Typical TEM images of three different structured $\mathrm{ZnO}$ tetrapods and the upper-right insets of the TEM images correspond to the SEAD patterns indicating the single-crystalline nature of ZnO tetrapods with (0001) orientation; $(c)$ HTEM image of the $\mathrm{ZnO}$ tetrapods with large hexagonal crown.
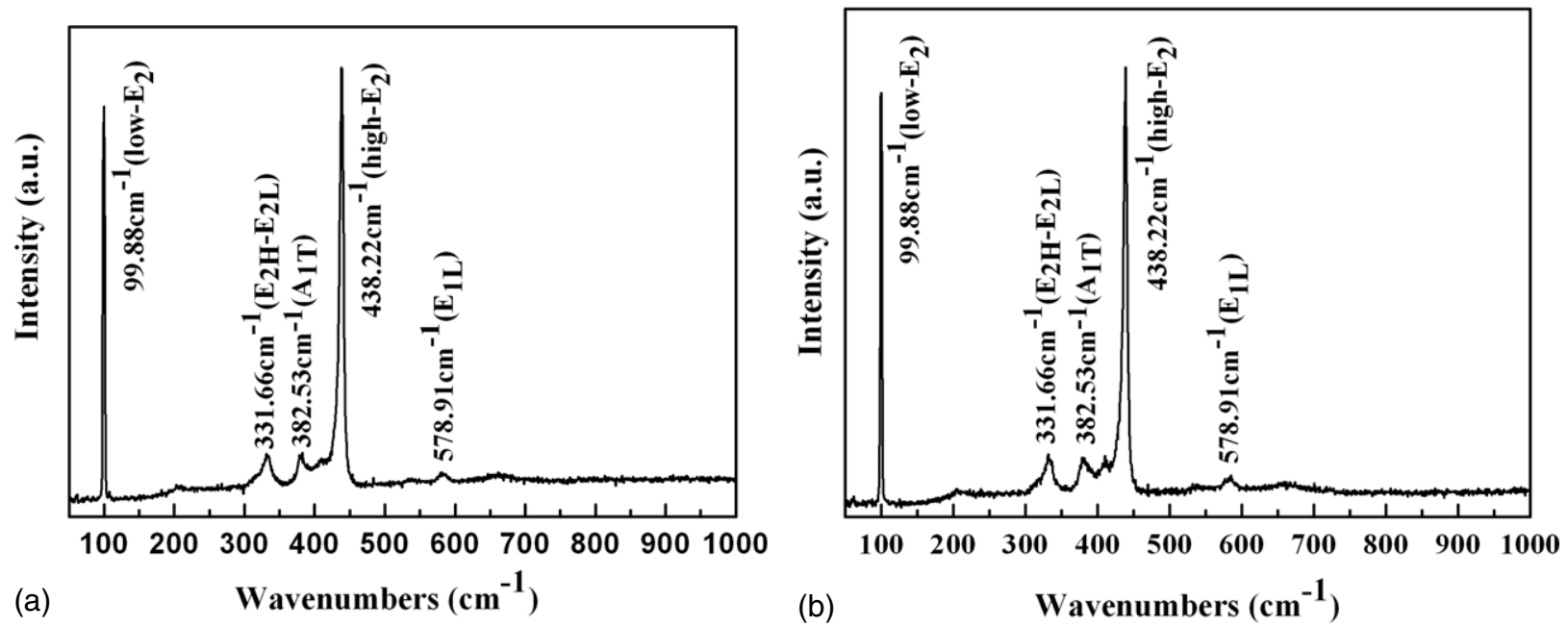

Figure 4. Raman scattering spectrum acquired from the $\mathrm{ZnO}$ tetrapods with hexagonal crown at room temperature fabricated at $(a)$ $T=630^{\circ} \mathrm{C}, \mathrm{O}_{2}: 15 \mathrm{sccm}$, Ar: $300 \mathrm{sccm}$ and $(b) T=680^{\circ} \mathrm{C}, \mathrm{O}_{2}: 25 \mathrm{sccm}$, Ar: $300 \mathrm{sccm}$.

crystals which grow along the (0001) orientation. Figures $3(d)$ and $(e)$ are the TEM images of the regular $\mathrm{ZnO}$ tetrapods fabricated at a temperature of $680{ }^{\circ} \mathrm{C}$, revealing that the $\mathrm{ZnO}$ with a flat top is about $2 \mu \mathrm{m}$ in length which is longer than those with the small hexagonal crown, but their legs are smaller. Because these two kinds of structured $\mathrm{ZnO}$ are too thick to be transparent to the incident electron beam, it is very difficult to obtain the HRTEM images. The SAED patterns taken from one of the legs show that the products are perfect single crystals with wurtzite structure and each leg grows along the (0001) direction, as is consistent with the result of XRD.

Room temperature Raman spectroscopy and PL measurements were performed to examine the optical properties of these regular tetrapods. Typical Raman spectra of these tetrapods are shown in figures $4(a)$ and $(b)$. There is not much difference between the two spectra for different structured tetrapods both in intensity and location. Two dominating and strong intensity peaks at $\sim 99.88 \mathrm{~cm}^{-1}$ and $\sim 438.22 \mathrm{~cm}^{-1}$, which are commonly observed in the wurtzite structure $\mathrm{ZnO}$ [14], are attributed to the low- and high- $\mathrm{E}_{2}$ mode of non-polar optical phonons, respectively. Two very small peaks at $\sim 331.6 \mathrm{~cm}^{-1}$ and $\sim 382.53 \mathrm{~cm}^{-1}$ correspond to $E_{2 \mathrm{H}}-E_{2 \mathrm{~L}}$ (multi phonon) and $A_{1 \mathrm{~T}}$ modes, respectively. The short and suppressed peak at $\sim 578.91 \mathrm{~nm}$ is assigned to the
$E_{1 \mathrm{~L}}$ mode due to the impurities and structural defects (oxygen vacancies and $\mathrm{Zn}$ interstitials) [15] of the samples.

The curve ' $a$ ' in figure 5 shows the room temperature PL spectrum of tetrapods with large hexagonal crown. As can be seen, it has two peaks: the near band-edge (NBE) ultraviolet (UV) peak at $\sim 393 \mathrm{~nm}(3.37 \mathrm{eV})$ and a green emission at $\sim 511 \mathrm{~nm}(2.43 \mathrm{eV})$. The former peak is considerably weaker compared with the latter, which falls in a very wide range $\sim 425-\sim 613 \mathrm{~nm}$. The origin of the green emission is still debatable. Scientists tend to assign it to deep levels induced by the single ionized oxygen vacancy in the $\mathrm{ZnO}$ [16]. It could also possibly have resulted from multiple shallow energy levels induced by the defects or their associates because there are some very weak peaks in tetrapods with large hexagonal crowns. The PL spectrum of tetrapods with small hexagonal crowns are shown by curve ' $b$ ' in figure 5 (the tetrapods with flat pods have the same spectra). The NBE peak is blue-shifted to $386 \mathrm{~nm}$; besides, it has no pronounced green emission peak except three very weak peaks at about 430,450 and $470 \mathrm{~nm}$. These indicated that this sample could have defects with very shallow energy level. Maybe, the reaction conditions (e.g. temperature, gas rate) have great influence on the surface state of the synthesized materials. The tetrapods with a large hexagonal crown have high surface-to-volume ratio due to its slender 


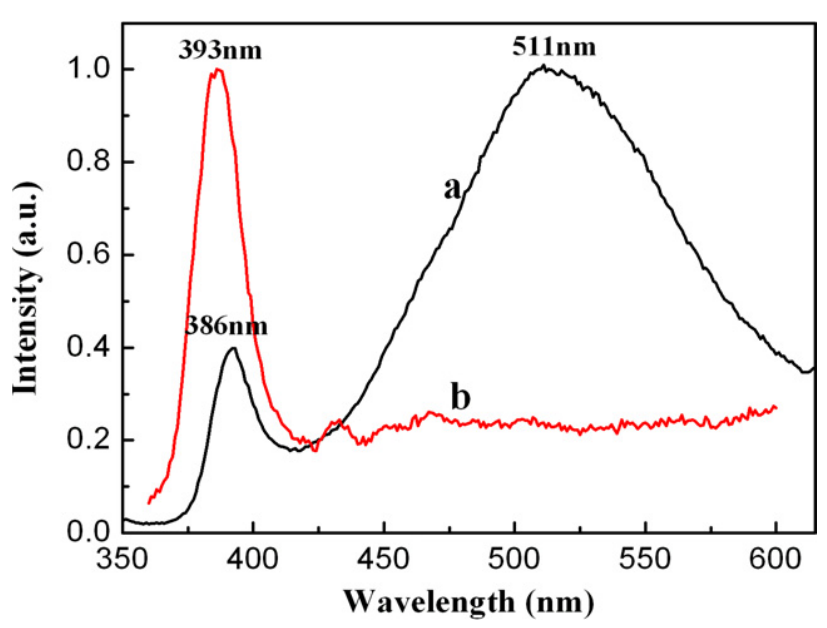

Figure 5. Room temperature PL spectrum of the $\mathrm{ZnO}$ tetrapods excited at $325 \mathrm{~nm}$ using Xe lamp as the resource. (a) $T=630^{\circ} \mathrm{C}$, $\mathrm{O}_{2}: 15 \mathrm{sccm}$, Ar: $300 \mathrm{sccm}$ and (b) $T=680^{\circ} \mathrm{C}, \mathrm{O}_{2}: 25 \mathrm{sccm}, \mathrm{Ar}$ : $300 \mathrm{sccm}$.

legs and the thin hexagonal crown; therefore, there may exist more oxygen vacancies than in other tetrapods. Consequently, the green emission peak at $511 \mathrm{~nm}$ is extraordinarily strong and quite wide.

So far, the growth mechanism for the growth of $\mathrm{ZnO}$ nanostrutures is still not quite clear. It is generally believed that $\mathrm{ZnO}$ tetrapods are formed by the vapour-solid (VS) mechanism rather than by the vapour-liquid-solid (VLS) model. The typical characteristic of the VLS mechanism is that the synthesized materials have metal particles capped at the end of them; however, these peculiar tetrapods were fabricated without the presence of any catalysts or other additives. There are many factors, including growth temperature, time, gas flow, substrate and catalyst, which are of importance to the growth and thus determine the shape and quality of structures. It is reported that the supply rate of oxygen determines the shape and length of tetrapods [17]. In these cases, maybe the temperature, together with the oxygen rate, is mainly responsible for these special structures. In the experiments, it was found that among these peculiar tetrapods there exists a common structured $\mathrm{ZnO}$ : peaked-leg tetrapods. Therefore, we can presume that all these regular tetrapods may originate from peaked-leg tetrapods. All experiments were carried out at a low oxygen partial pressure and at temperatures much higher then the melting point of zinc; therefore, the concentration of $\mathrm{O}_{2}$ is low, while that of $\mathrm{Zn}$ is considerably high. For the $\mathrm{ZnO}$ tetrapods with a hexagonal crown, the partial pressure of oxygen is very low; the oxygen is consumed quickly in a short period. The sudden change in the reaction atmosphere results in the change in the growth orientation and produces $\mathrm{ZnO}$ tetrapods with hexagonal crowns. As for the other two, they are grown at a higher oxygen ratio, so the partial pressure of oxygen does not change so abruptly as to change the growth direction. Of course, the $\mathrm{ZnO}_{x}$ will also gather at the tips of the peak-shaped $\mathrm{ZnO}$ for the same reason as mentioned above. They will grow layer by layer according to the symmetry of the $\mathrm{ZnO}$ crystal and finally result in very regular legs. But, in different regions of the boat, there is little difference in the reaction conditions, such as temperature and gas rate, determining the difference in configuration of the products in different regions. However, the growth mechanism mentioned is just a speculated result and it needs further support from experiment and theory.

\section{Conclusions}

In summary, three different kinds of peculiar structured $\mathrm{ZnO}$ tetrapods have been successfully synthesized by changing the growth temperature. SAED pattern and XRD results suggest that they are single crystals with wurtzite structure and grow along the (0001) direction. PL spectra of these structured $\mathrm{ZnO}$ reveal that they have unique optical properties, which suggest potential applications in the field of nanodevices.

\section{Acknowledgments}

This work was supported by the Distinguished Young Scholar Fund of National Natural Science Foundation of China (NSFC, Grant No 10225209), a key project of the Chinese Academy of Sciences (Grant No KJCX-SW-L2) and the NSFC project (Grant No 90305020).

\section{References}

[1] Ryu Y R, Zhu S, Budai J D, Chanandrasekhar H R, Miceli P F and White H W 2000 J. Appl. Phys. 88201

[2] Service R F 1997 Science 276895

[3] Arnold M S, Avouris P, Pan Z W and Wang Z L 2003 J. Phys. Chem. B 107659

[4] Cui Y, Wei Q Q, Park H K and Lieber C M 2001 Science 29317

[5] Sekhar R C, Hari K S, Vivekchand S R C, Govindaraj A and Rao C N R 2005 Chem. Phys. Lett. 418582

[6] O'Regan B, Schwarthz D T, Zakeeruddin S M and Gratzel M 2000 Adv. Mater. 121263

[7] Nagata T, Shimura T, Asida A, Fujimura N and Ito T 2002 J. Cryst. Growth 273533

[8] Yumoto H, Inoue Y, Lee S J, Sako T and Nishiyama K 1999 Thin Solid Films 34538

[9] Chen J J, Zeng F, Li D M, Niu J B and Pan F 2005 Thin Solid Films $\mathbf{4 8 5} 257$

[10] Fortunato E, Barquinha P, Pimentel A, Gonçalves A, Marques A, Pereira L and Martins R 2005 Thin Solid Films 487205

[11] Pan Z W, Dai Z R and Wang Z L 2001 Science 2911947

[12] Kong Y C, Yu D P, Zhang B, Fang W and Feng S Q 2001 Appl. Phys. Lett. 78407

[13] Gao P X, Ding Y, Mai W J, Hughes W L, Lao C S and Wang Z L 2005 Science 3091702

[14] Xing Y J, Xi Z H, Xue Z Q, Zhang X D, Song J H, Wang R M, Xu J, Song Y, Zhang S L and Yu D P 2003 Appl. Phys. Lett. 831689

[15] Vanheusden K, Seager C H, Warren W L, Tallant D R and Voigt J A 1996 J. Appl. Phys. 797983

[16] Heo Y W, Norton D P and Pearton S J 2005 J. Appl. Phys. 98073502

[17] Kitano M, Hamabe T and Maeda S 1990 J. Cryst. Growth 102965 